\title{
Randomized controlled study of the impact of a participatory patient care plan among primary care patients with common chronic diseases: a one-year follow-up study
}

Nina Tusa ${ }^{1,2,3^{*}}$, Hannu Kautiainen ${ }^{2,4}$, Pia Elfving ${ }^{5}$, Sanna Sinikallio ${ }^{6}$ and Pekka Mäntyselkä ${ }^{1,2}$

\begin{abstract}
Backround: Chronic diseases and multimorbidity are common in the ageing population and affect the health related quality of life. Health care resources are limited and the continuity of care has to be assured. Therefore it is essential to find demonstrable tools for best treatment practices for patients with chronic diseases.

Our aim was to study the influence of a participatory patient care plan on the health-related quality of life and disease specific outcomes related to diabetes, ischemic heart disease and hypertension.
\end{abstract}

Methods: The data of the present study were based on the Participatory Patient Care Planning in Primary Care. A total of 605 patients were recruited in the Siilinjärvi Health Center in the years 2017-2018 from those patients who were followed up due to the treatment of hypertension, ischemic heart disease or diabetes. Patients were randomized into usual care and intervention groups. The intervention consisted of a participatory patient care plan, which was formulated in collaboration with the patient and the nurse and the physician during the first health care visit.

Health-related quality of life with the 15D instrument and the disease-specific outcomes of body mass index (BMI), low density lipoprotein cholesterol (LDL-C), hemoglobin A1c (HBA1C) and blood pressure were assessed at the baseline and after a one-year follow-up.

Results: A total of 587 patients with a mean age of 69 years were followed for 12 months. In the intervention group there were 289 patients (54\% women) and in the usual care group there were 298 patients (50\% women). During the follow-up there were no significant changes between the groups in health-related quality and diseasespecific outcomes.

Conclusions: During the 12-month follow-up, no significant differences between the intervention and the usual care groups were detected, as the intervention and the usual care groups were already in good therapeutic equilibrium at the baseline.

\footnotetext{
* Correspondence: nina.tusa@uef.fi

${ }^{1}$ Institute of Public Health and Clinical Nutrition, University of Eastern Finland,

P.O. Box 1627, Fl-70211 Kuopio, Finland

${ }^{2}$ Primary Health Care Unit, Kuopio University Hospital, Kuopio, Finland

Full list of author information is available at the end of the article
}

(C) The Author(s). 2021 Open Access This article is licensed under a Creative Commons Attribution 4.0 International License, which permits use, sharing, adaptation, distribution and reproduction in any medium or format, as long as you give appropriate credit to the original author(s) and the source, provide a link to the Creative Commons licence, and indicate if changes were made. The images or other third party material in this article are included in the article's Creative Commons licence, unless indicated otherwise in a credit line to the material. If material is not included in the article's Creative Commons licence and your intended use is not permitted by statutory regulation or exceeds the permitted use, you will need to obtain permission directly from the copyright holder. To view a copy of this licence, visit http://creativecommons.org/licenses/by/4.0/ The Creative Commons Public Domain Dedication waiver (http://creativecommons.org/publicdomain/zero/1.0/) applies to the data made available in this article, unless otherwise stated in a credit line to the data. 
Trial registration: ClinicalTrials.gov Identifier: NCT02992431. Registered 14/12/2016

Keywords: Primary health care, Patient care planning, Care plan, Treatment plan, Impact, Chronic diseases, Ageing population

\section{Backround}

Patient engagement and activation in self-care, patientcentered care, self-management support and shared decision-making are important primary health care and health policy issues [1-4]. Populations around the world are rapidly ageing and the number of chronic diseases and long-term health problems is growing [5-7]. Health care resources are limited and the continuity of care has to be assured. One of the tools for answering this demand and gather information together is a care or a treatment plan. In Finland, the National Institute for Health and Welfare has issued a recommendation and guidance on the use of the structured care plan mentioned in the Health Care Act [8].

An individual or personalised care plan or a treatment plan is a detailed approach to care goals tailored to an individual patient's needs. In this article, we use the term care plan. It is a mutual agreement between the patient and the health staff regarding the goals the patient is ready and willing to achieve to improve his health and well-being. It also describes what kind of support the patient needs and what the treatment targets are from a medical perspective [9].

Although various care plans have been used in Finland and elsewhere for decades, there is still little research on their effectiveness $[8,10-15]$. Earlier Finnish care plan projects have reported a decrease in the number of health care visits in the long run and improvements in blood lipid levels, blood pressure levels and body mass index (BMI) $[12,16,17]$. In Australia (2009), the use of a care plan improved the treatment of depressed patients, reduced their 10-year risk of cardiovascular disease, and increased their physical activity $[10,18]$. The care plan also appears to have the potential to shift the focus from the treatment of a single disease to acknowledging the treatment of the ensemble of all chronic diseases [10, 18]. According to the Cochrane Review, it has a small positive impact on diabetes management, blood pressure, asthma balance, depression, and self-care, but not on perceived health [19]. The impact of a care plan was found to be greater with more care plan rounds, more frequent patient contacts with health care, and when the physician treating the patient the most was involved in the process.

The pivotal shift in the care plan process is from reactive care to a proactive approach and patient-centred goal setting and action planning. Patients themselves, through their daily actions and choices, determine - to a large extent - their need for care and health care outcomes. Although there already is some research on selfmanagement support strategies in primary care practices [4], it is not known how to support the patient best to achieve their own goals in real life. Moreover, more research is needed on how to find and motivate particularly those patients who are reluctant to invest in their well-being.

The health related quality of life (HRQOL) is an important outcome of the health care playing a notable role in patients with chronic diseases [20]. The HRQOL is dependent on the number of the chronic diseases and is higher with the lighter burden of diseases [21]. For example, hypertension and diabetes are experienced with a minor decrease in HRQOL than depression, cancer, asthma and chronic obstructive pulmonary disease [22, 23]. One purpose of the care plan is to support continuity which is particularly important in patients with chronic illnesses and improving the quality of care [24-29]. However, in the health care there is a continuous need in balancing with the resources and need. Therefore, we need more research on applying and implementing integrative methods of supporting the continuity and coordination of care.

The ageing population and increased prevalence of chronic diseases with the increased need for supporting continuity and involving patients in their health care are important reasons for the health care plan. The process of the health care plan ties the resources of different health care professionals. However, the benefits related to treatment and HRQOL among primary health care patients with common chronic diseases are vague. Therefore, in the present real-life randomized study, the aim was to investigate whether a participatory patient care planning intervention has any impact on the health related quality of life (HRQOL) and clinical outcomes in primary care patients with hypertension, ischemic heart disease or diabetes.

\section{Methods}

\section{Context}

The study was a real-life randomized control study integrated in the everyday work in a health center. The data of the present study were based on the Participatory Patient Care Planning in Primary Care (4PHC) (ClinicalTrials.gov Identifier: NCT02992431). The study was conducted in semi urban municipality Siilinjärvi, Finland, with a 
population of 21,657 residents at the end of 2017, located in the vicinity of a large town. The mean-age of the population in Siilinjärvi was 41 years in 2017 [30].

\section{Patients}

The study population was based on adult residents (age $\geq 18$ years) who were living in the municipality of Siilinjärvi, and had diabetes, ischemic heart disease or hypertension. They were registered in the electronic patient records in the Siilinjärvi Health Center. The Siilinjärvi Health Center is the main primary health service responsible for the health of the population in primary care in the municipality. The participating patients were recruited from those patients who had a follow-up visit due to their disease between February 2017 and March 2018. The disease groups were organized according to the degree of severity of the disease so that the hypertensive patients had only hypertension, ischemic heart disease patients could have also had hypertension and the diabetes patients could have had all three diseases. Of the diabetes patients, 58 had ischemic heart disease (24\%) and 193 had hypertension $(80 \%)$. Of the patients with ischemic heart disease, 59 (57\%) had hypertension. In the diabetes group there were both type 1 and 2 diabetes patients. In addition to these diseases, patients could also have other diseases. The baseline results have been presented in more detail in our previous article [31].

A total of 800 patients were informed about the study. In total, 622 patients agreed to participate, but 17 cancelled their participation afterwards. Of the 605 participants, 587 patients completed all the data needed for this analysis. The flow of the study is presented in Fig. 1.

\section{Randomization}

The participants were randomly assigned to an intervention group or a control group receiving usual care (UC). The randomization was stratified according to disease and was carried out by a statistician outside the research team. The invitation letters in sealed envelopes were arranged according to the randomization. Before the scheduled appointment, the study nurse sent the concealed invitation letter to the patients, who had given a written consent to the study. It was not possible to blind participants, health professionals or researchers due to the nature of the intervention.

\section{Intervention}

Intervention consisted of the participatory patient care plan (PPCP). It included the patient activation questionnaire form and a request to attach records of selfmonitored measurements, such as blood sugar and blood pressure values. After advance preparation, the patient was invited to visit the nurse and a general practitioner and a participatory care plan was mutually accepted by the patient and the health staff. All medical staff received short training on the preparation of a PPCP and a written instruction on the research protocol was distributed to each office, which also included a care plan formulation guideline. At the nurse visit, each patient had an appointment for 30-60 min in which the patient and the nurse started the discussion about his or her lifestyle, individual goals for the treatment and conducted the measurements (blood pressure in sitting position, waist measurement, weight and length). A fasting blood sample was drawn in a laboratory after $12 \mathrm{~h}$ of fasting before the physician's visit. Then the patient visited the general practitioner for $30-40 \mathrm{~min}$ for the follow-up and discussion about the treatment goals and follow-up plan resulting in the written PPCP. Briefly, the personalized care plan process includes the following steps as presented at Fig. 2: preparation (A), goal setting (B), action planning $(C)$, documenting $(\mathrm{D})$, coordinating (E), supporting (F) and reviewing (G) [9].

See detailed description of the PPCP in Table 1.

\section{Usual care}

Participants in the UC group had the same measurements as the intervention group in a nurse's office and at the same visit they met the general practitioner (GP) or the GP phoned a follow-up call.

\section{Outcomes}

Primary outcomes were health-related quality of life (HRQOL) measured with the 15D [32], and diseasespecific outcomes: blood pressure, glycemic control measured with hemoglobin A1c (HbA1C), dyslipidemia treatment status measured with low-density lipoprotein cholesterol (LDL-C) and BMI.

The $15 \mathrm{D}$ is a generic, comprehensive, standardized, self-administered measure of health-related quality of life. The 15D questionnaire includes the following $15 \mathrm{di}-$ mensions: breathing, mental function, speech (communication), vision, mobility, usual activities, vitality, hearing, eating, elimination, sleeping, distress, discomfort and symptoms, sexual activity and depression. Each dimension is divided into 5 levels. The maximum score is 1 (no problems on any dimension) and the minimum score is 0 (being dead). The smallest change in quality of life detected by the $15 \mathrm{D}$ is 0.015 [33].

A fasting blood sample for $\mathrm{HbA1C}$ and LDLcholesterol was drawn in a laboratory after $12 \mathrm{~h}$ of fasting. The standard procedure of the Kuopio University Hospital laboratory was used in the analysis.

A trained nurse measured blood pressure in a sitting position after $10 \mathrm{~min}$ of sitting. Diastolic blood pressure (DBP) and systolic blood pressure (SBP) were recorded and mean arterial pressure (MAP) was calculated [DP+ $1 / 3$ (SBP-DBP)]. The nurse also measured weight in light 


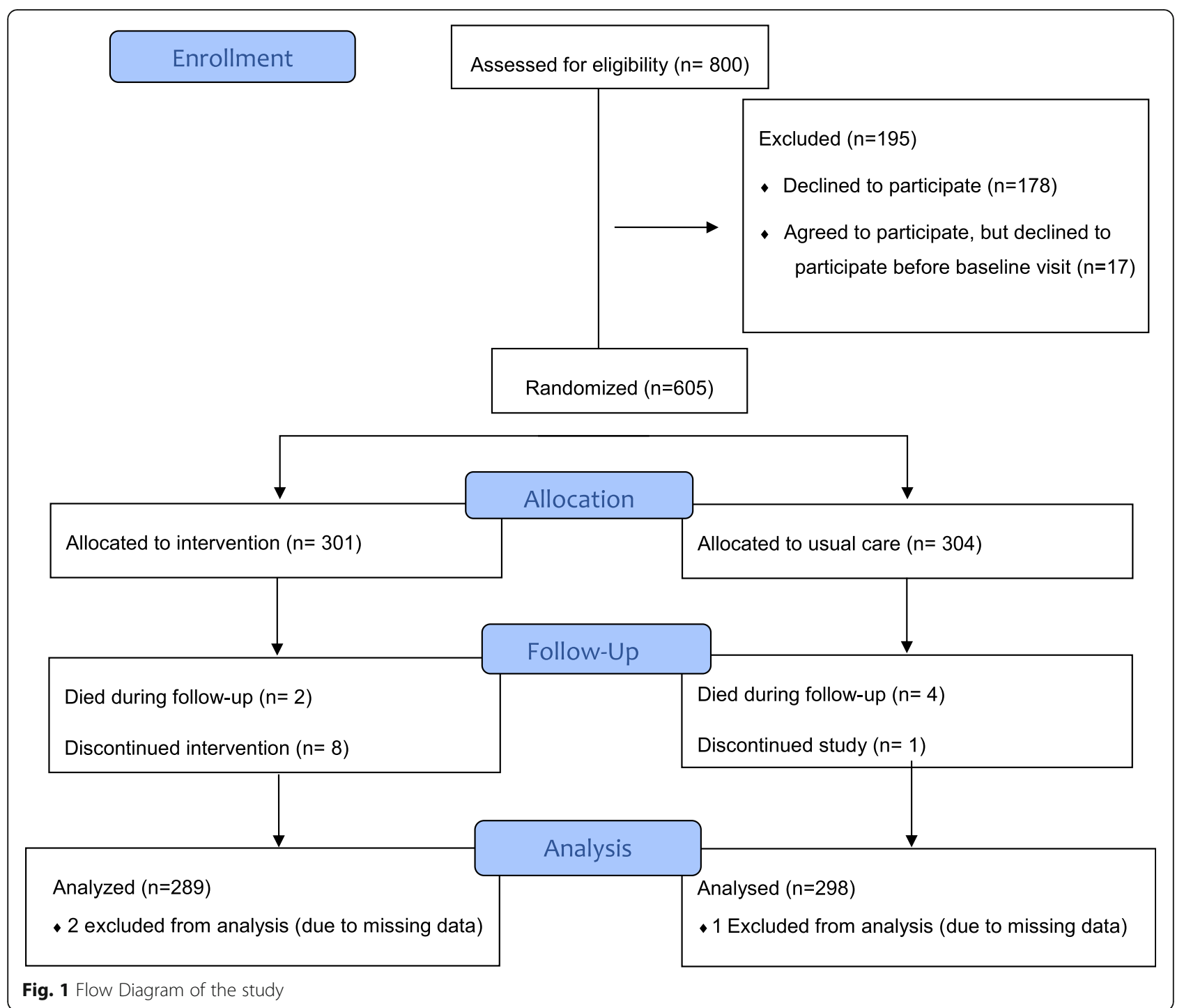

clothing and height, and the body mass index was calculated as weight $(\mathrm{kg}) /$ height $(\mathrm{m})^{2}$.

\section{Other measurements}

Educational background and relationship status were asked in the questionnaire. Accordingly, the presence of other chronic diseases was asked. Depressive symptoms were measure with the 21-item Beck's Depression Inventory [34]. The number of drinks per week and current smoking (yes or no and number of cicarettes per day) habits were asked in the question form.

Physical activity was measured by the Kasari fit index [35]. The FIT index was used to assess the level of physical activity and was calculated according to the participant's responses on an activity questionnaire scale: $[$ FIT $=$ Frequency $(\mathrm{F}) \times$ Intensity $(\mathrm{I}) \times$ Time $(\mathrm{T})]$. The participant's frequency was determined by how many days per week he/she exercised on a five-point scale with 1 representing less than once per month and 5 representing 6 or 7 times per week. Intensity was set on a five-point scale with 1 representing light aerobic activity such as normal walking and 5 representing high intensity such as running. Time was determined on a four point scale with 1 representing less than $10 \mathrm{~min}$ and 4 representing greater than 30 min. FIT scores can range from 1 (low activity) to 100 (high activity) and are divided into four classes 0-12 points, $13-36$ points, 37-63 poits and over 64 points [36].

\section{Statistical methods}

Sample size calculations were based on the 15D, primary outcome measure. A 0.015 change in this score has been considered a clinically meaningful difference between intervention and control arms [33]. To ensure 85\% power to detect this difference in the $15 \mathrm{D}$ with type 1 


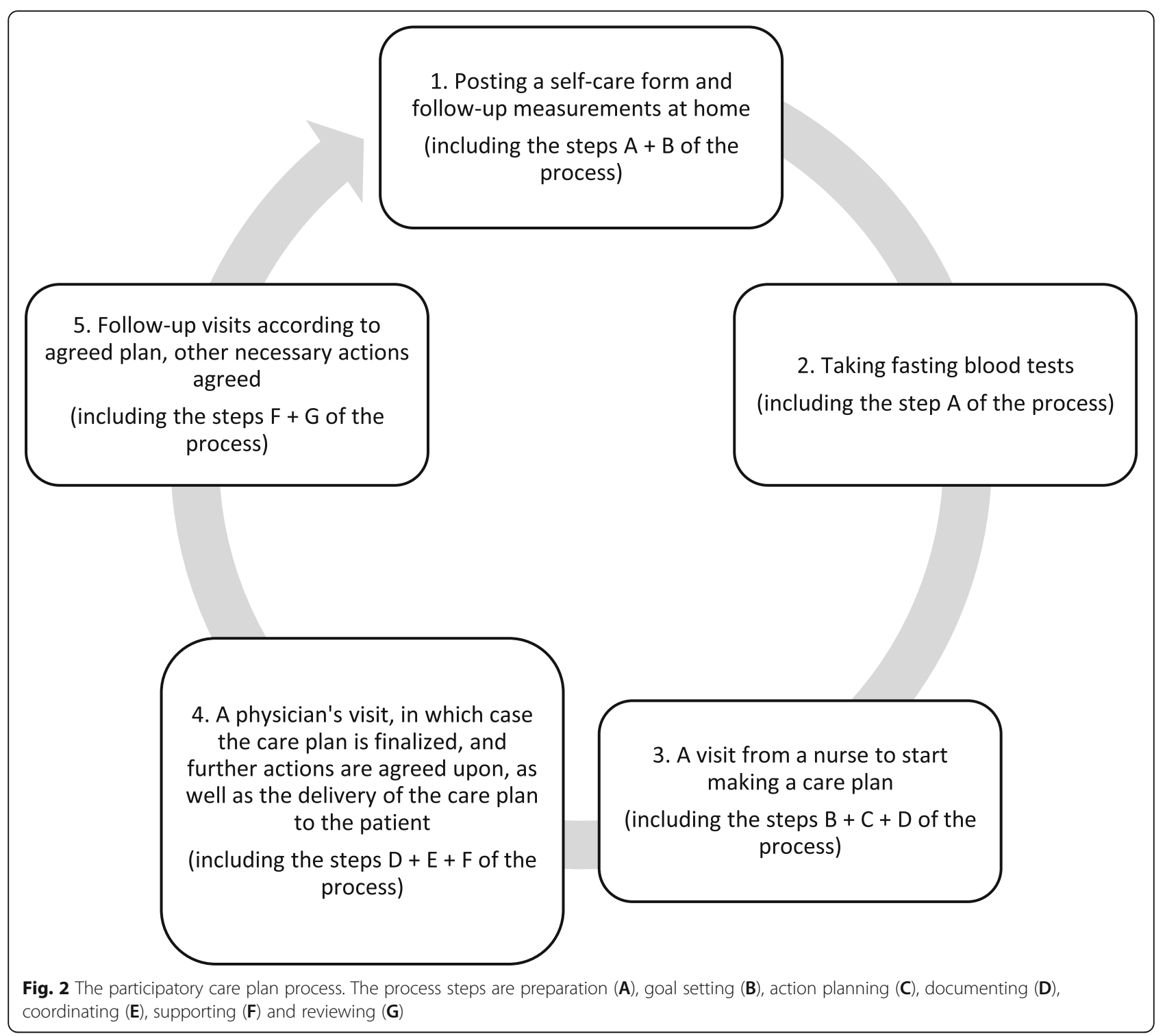

error $5 \%$ size $(=0.05$, power $=85 \%)$, the sample size would be 300 per group. We expected the drop-out rate over time to be about $10 \%$.

The intention-to-treat analysis was applied in all analyses. Data were presented as means with standard deviation (SD) and as counts with percentages. Statistical comparisons between groups were done using a t-test and Chi-square test. The adjusted mean changes of outcome measures between the baseline and 12-month measures were assessed using analysis of covariance

Table 1 Participatory patient care plan framework themes

\begin{tabular}{ll}
\hline Theme & Description \\
\hline Need for care & Narrative description of the need for care (patient perspective) \\
Goal of treatment & Narrative description of the goals of treatment (patient perspective) \\
Treatment implementation and means & Narrative description of the implementation and means of treatment \\
Support, monitoring and evaluation & $\begin{array}{l}\text { Narrative Description of support for the realization of the patient care plan, monitoring and } \\
\text { assessment of the effects of treatment } \\
\text { The current medication }\end{array}$ \\
Medication & $\begin{array}{l}\text { Deliver a care plan to the patient. The care plan is mailed to the patient by post or he/she } \\
\text { can view it My Kanta digital services for browsing his/her medical records and prescriptions. }\end{array}$ \\
\end{tabular}


(ANCOVA), with baseline measure as covariates. Effect sizes (Cohen's d) were calculated to determine the magnitude of the difference between the means of the groups. Effect sizes of $0.20,0.50$ and 0.80 were considered small, medium, and large, respectively [37, 38]. Confidence intervals (CIs) for the effect sizes were obtained by bias-corrected bootstrapping (5000 replications). The normality of the variables was evaluated graphically and by the Shapiro-WilkW test. The Stata 16.1 (StataCorp LP; College Station, Texas, TX, USA) statistical package was used for the analysis.

All methods were carried out in accordance with relevant guidelines and regulations.

The study protocol was approved by the Research Ethics Committee of the Northern Savo Hospital District (410/2016). ClinicalTrials.gov Identifier: NCT02992431. Registered 14/12/2016.

\section{Results}

There were 289 patients (54\% women) in the intervention group and 298 patients (50\% woman) in the usual care group. The mean age in both groups was 69 years. The basic charasteristics of the two study groups are presented in Table 2.

After a 12-month follow-up, there was a significant decrease in systolic blood pressure and mean arterial pressure in the usual care and intervention groups when all participants were assessed together (Table 3). There were no significant differences in the changes of the 15D, BMI, LDL-C, HbA1C or blood pressure between the intervention group and usual care group.

Table 4 shows the disease-specific changes. In patient with hypertension, $\mathrm{HbA} 1 \mathrm{C}$ increased and blood pressure decreased in both groups. In patients with ischemic heart disease, HbA1C increased in both groups. In patients with diabetes, BMI decreased in the intervention group. There were no significant differences in the changes in the $15 \mathrm{D}, \mathrm{BMI}, \mathrm{LDL}-\mathrm{C}, \mathrm{HbA} 1 \mathrm{C}$ or blood pressure between intervention and usual care in any of the the disease groups.

In Fig. 3, the difference in change between the two groups is presented by Cohen's effect size. There were no significant changes in the 15D, BMI, LDL-C, HbA1C or MAP in any disease group between the intervention and the usual care, athough change in BMI favoured slightly the intervention in patients with diabetes.

\section{Discussion}

The intervention group did not seem to benefit from the participating patient care plan significantly after a twelve-month follow-up compared with the usual care group in any disease groups measured with healthrelated quality of life (HRQOL) or in disease-specific outcomes. There was a slight decrease in the body mass index within the diabetes group but not in the usual care at the twelve-month follow-up although the difference between intervention and usual care was not quite significant. In general, only minor (or no) changes were detected within groups.

We found few studies after the Cochrane review in addition to our study that have a follow-up while measuring the impact of care plans. One study concerned the diseases studied in our study. An observational, retrospective study of type 2 diabetes patients in primary care with mean follow-up time of 14 months showed statistical significant decrease in LDL-C, blood pressure and BMI [16]. A telephone interview study with female asthma patients after a two-year follow-up showed greater medication adherence and satisfaction with clinical care among patients having a negotiated care plan, but no significant associations between a negotiated care plan, asthma control and urgent care use [15]. In a primary care-based 1 year follow-up study in Australia, the use of a care plan improved the treatment of depressed patients, reduced their 10-year risk for cardiovascular disease, and increased their physical activity [10, 18]. This study was The TrueBlue model of collaborative care using practice nurses as case managers, the care plan being not the only intervention used to improve the care of depressive patients alongside diabetes or heart disease. An implementation study from the UK with primary care patients did not show a significant difference in mean vitality after a one-year follow-up [14]. Our findings are in line with these studies although in the Australian study, the influence was greater maybe partly due to the enhanced visits to the practice nurse and general practitioner every 3 months during the twelvemonth follow-up. In our study, the patients continued their individually planned follow-up with their physician after 12-24 months or the nurse after 6-12 months depending on their individual need.

The trend of our findings is parallel with earlier research on diabetes management as it displayed a small positive impact on BMI although not significant on diabetes management. According to the Cochrane Review, the care plan has a small positive impact on diabetes management, blood pressure, asthma balance, depression, and self-care, but not on perceived health [19]. The impact of the care plan was found to be greater with more care plan rounds, more frequent patient contacts with health care, and if there was continuity with the same physician in the care plan process. In a Finnish cross-sectional study, a personalized care plan was positively associated with better clinical outcomes in type 2 diabetes patients such that patients who had a copy of their care plan were significantly more likely to achieve the systolic blood pressure target and low-density lipoprotein target and to use statins [12]. 
Table 2 Characteristics of the patients

\begin{tabular}{|c|c|c|c|}
\hline & Intervention & Usual care & $P$-value \\
\hline & $N=289$ & $N=298$ & \\
\hline Women, n (\%) & $157(54)$ & $150(50)$ & 0.33 \\
\hline Age, mean (SD) & $69(9)$ & $69(9)$ & 0.35 \\
\hline Living with a spouse, n (\%) & $215(74)$ & $215(72)$ & 0.54 \\
\hline Number of education years, mean (SD) & $10.1(2.9)$ & $10.5(3.3)$ & 0.63 \\
\hline Retired, n (\%) & $239(83)$ & $256(86)$ & 0.29 \\
\hline Smoking, n (\%) & $32(11)$ & $29(10)$ & 0.59 \\
\hline Alcohol consumption, n (\%) & & & 0.65 \\
\hline Not at all & $67(23)$ & $81(27)$ & \\
\hline one times per month or less & $101(35)$ & $87(29)$ & \\
\hline 2-4 times per month & $76(27)$ & $91(31)$ & \\
\hline 2-3 times per month & $31(11)$ & $30(10)$ & \\
\hline 4 or more times per month & $11(4)$ & $7(2)$ & \\
\hline Moves without mobility aids, n (\%) & $264(91)$ & $270(91)$ & 0.75 \\
\hline Physical activity ${ }^{\mathrm{a}}$, mean (SD) & $41(20)$ & $40(20)$ & 0.44 \\
\hline Fasting plasma glucose, mmol/l, mean (SD) & $6.55(1.19)$ & $6.61(1.33)$ & 0.58 \\
\hline Beck depression index score, mean (SD) & $5.9(4.9)$ & $5.7(4.9)$ & 0.56 \\
\hline \multicolumn{4}{|l|}{ Diseases, n (\%) } \\
\hline Diabetes mellitus & $124(42.9)$ & $117(39.3)$ & 0.37 \\
\hline Hypertension & $230(79.6)$ & $246(82.6)$ & 0.36 \\
\hline Ischemic heart disease & $77(26.6)$ & $86(28.9)$ & 0.55 \\
\hline Atrial fibrillation & $38(13.1)$ & $33(11.1)$ & 0.44 \\
\hline Cardiac failure, insufficiency & $18(6.2)$ & $21(7.0)$ & 0.69 \\
\hline Musculoskeletal disorders & $155(53.6)$ & $157(52.7)$ & 0.82 \\
\hline Dementia & $5(1.7)$ & $2(0.7)$ & 0.28 \\
\hline Other neurological diseases & $14(4.8)$ & $14(4.7)$ & 0.99 \\
\hline Depression or other psychiatric disorders & $21(7.3)$ & $14(4.7)$ & 0.22 \\
\hline Asthma or chronic obstructive pulmonary disease & $39(13.5)$ & $40(13.4)$ & 0.98 \\
\hline Cancer & $3(1.0)$ & $1(0.3)$ & 0.37 \\
\hline Number of diseases, mean (SD) & $2.5(1.3)$ & $2.5(1.2)$ & 0.64 \\
\hline
\end{tabular}

$\%$ percentage, $S D$ standard deviation, $n$ number

${ }^{a}$ Kasari FIT index

Table 3 Baseline values and changes after 12 months of outcome measures of patients in intervention and usual care groups

\begin{tabular}{|c|c|c|c|c|c|c|}
\hline & \multicolumn{2}{|l|}{ Baseline } & \multicolumn{2}{|l|}{ Change } & \multicolumn{2}{|c|}{$P$-value** } \\
\hline & $\begin{array}{l}\text { Intervention } \\
\text { Mean (SD) }\end{array}$ & $\begin{array}{l}\text { Usual care } \\
\text { Mean (SD) }\end{array}$ & $\begin{array}{l}\text { Intervention } \\
\text { Mean }(95 \% \mathrm{Cl})\end{array}$ & $\begin{array}{l}\text { Usual care } \\
\text { Mean }(95 \% \mathrm{Cl})\end{array}$ & Crude & Adjusted $^{\mathrm{a}}$ \\
\hline \multicolumn{7}{|l|}{ ALL } \\
\hline HRQOL, 15D score & $0.867(0.095)$ & $0.876(0.093)$ & $0.004(-0.003$ to 0.01$)$ & $-0.002(-0.009$ to 0.005$)$ & 0.26 & 0.42 \\
\hline Body mass index, kg/m2 & $29.2(5.2)$ & $29.5(5.8)$ & $-0.17(-0.35$ to 0.01$)$ & $-0.04(-0.19$ to 0.11$)$ & 0.28 & 0.25 \\
\hline LDL-C, mmol/l & $2.67(0.97)$ & $2.59(0.92)$ & $-0.01(-0.09$ to 0.09$)$ & $0.06(-0.02$ to 0.14$)$ & 0.32 & 0.45 \\
\hline $\mathrm{HbA} 1 \mathrm{C}, \mathrm{mmol} / \mathrm{mol}$ & $40.9(8.2)$ & $41.8(8.8)$ & $0.4(-0.1$ to 1.0$)$ & $0.1(-0.5$ to 0.8$)$ & 0.46 & 0.83 \\
\hline \multicolumn{7}{|l|}{ Blood pressure $(\mathrm{mmHg})$} \\
\hline Systolic & $148(17)$ & $148(18)$ & $-3.3(-5.6$ to -1.0$)$ & $-2.5(-4.5$ to -0.5$)$ & 0.62 & 0.64 \\
\hline Diastolic & $82(11)$ & $82(10)$ & $-1.1(-2.4$ to 0.1$)$ & $-1.1(-2.2$ to 0.0$)$ & 0.94 & 0.90 \\
\hline Mean arterial pressure & $103(11)$ & $103(11)$ & $-1.9(-3.3$ to -0.4$)$ & $-1.6(-2.8$ to -0.3$)$ & 0.75 & 0.74 \\
\hline
\end{tabular}

SD standard deviation, HRQOL health-related quality of life, LDL-C low-density lipoprotein cholesterol, HbA1C Haemoglobin A1c

** $P$-value for the differences in the changes between the intervention group and usual care group

${ }^{a}$ ANCOVA: adjusted for baseline value 
Table 4 Baseline values and change after 12 months of outcome measures in intervention and usual care groups for the patients having hypertension, ischemic heart disease and diabetes

\begin{tabular}{|c|c|c|c|c|c|c|}
\hline & \multicolumn{2}{|l|}{ Baseline } & \multicolumn{2}{|l|}{ Change } & \multicolumn{2}{|c|}{$P$-value** } \\
\hline & $\begin{array}{l}\text { Intervention } \\
\text { Mean (SD) }\end{array}$ & $\begin{array}{l}\text { Usual care } \\
\text { Mean (SD) }\end{array}$ & $\begin{array}{l}\text { Intervention } \\
\text { Mean }(95 \% \mathrm{Cl})\end{array}$ & $\begin{array}{l}\text { Usual care } \\
\text { Mean }(95 \% \mathrm{Cl})\end{array}$ & Crude & Adjusted $^{a}$ \\
\hline \multicolumn{7}{|l|}{ Hypertension } \\
\hline HRQOL, 15D score & $0.880(0.083)$ & $0.891(0.082)$ & $0.007(-0.004$ to 0.017$)$ & $-0.001(-0.011$ to 0.10$)$ & 0.34 & 0.52 \\
\hline Body mass index, kg/m2 & $27.9(4.6)$ & $27.9(5.0)$ & $0.06(-0.24$ to 0.35$)$ & $-0.04(-0.24$ to 0.16$)$ & 0.59 & 0.58 \\
\hline LDL-C, mmol/l & $3.04(0.95)$ & $2.95(0.93)$ & -0.07 ( -0.23 to 0.09$)$ & $0.05(-0.10$ to 0.20$)$ & 0.27 & 0.37 \\
\hline $\mathrm{HbA} 1 \mathrm{C}, \mathrm{mmol} / \mathrm{mol}$ & $36.8(4.3)$ & $37.9(3.6)$ & 0.6 (0.1 to 1.0$)$ & 0.3 (0.1 to 1.0$)$ & 0.41 & 0.98 \\
\hline \multicolumn{7}{|l|}{ Blood pressure (mmHg) } \\
\hline Systolic & $144(16)$ & $144(17)$ & $-4.2(-8.0$ to -0.4$)$ & $-4.0(-7.1$ to -1.0$)$ & 0.95 & 0.65 \\
\hline Diastolic & $83(10)$ & $85(11)$ & $-2.0(-4.0$ to -0.0$)$ & $-2.2(-3.9$ to -0.5$)$ & 0.91 & 0.64 \\
\hline Mean arterial pressure & $105(11)$ & $106(11)$ & $-2.7(-5.1$ to -0.4$)$ & $-2.8(-4.7$ to -0.9$)$ & 0.97 & 0.62 \\
\hline \multicolumn{7}{|l|}{ Ischemic heart disease } \\
\hline HRQOL, 15D score & $0.860(0.085)$ & $0.860(0.106)$ & $0.001(-0.014$ to 0.015$)$ & $-0.012(-0.029$ to 0.005$)$ & 0.28 & 0.28 \\
\hline Body mass index, kg/m2 & $28.1(4.4)$ & $28.3(5.5)$ & -0.40 ( -0.87 to 0.08$)$ & $-0.20(-0.49$ to 0.09$)$ & 0.47 & 0.40 \\
\hline LDL-C, mmol/l & $2.21(0.74)$ & $2.23(0.80)$ & $0.09(-0.09$ to 0.27$)$ & $0.05(-0.12$ to 0.22$)$ & 0.77 & 0.78 \\
\hline $\mathrm{HbA} 1 \mathrm{C}, \mathrm{mmol} / \mathrm{mol}$ & $38.5(3.9)$ & $38.3(4.7)$ & 0.7 (0.1 to 1.4) & $0.3(-0.4$ to 1.0$)$ & 0.40 & 0.31 \\
\hline \multicolumn{7}{|l|}{ Blood pressure (mmHg) } \\
\hline Systolic & $144(19)$ & $143(16)$ & $-3.1(-7.5$ to 1.3$)$ & $-0.1(-4.4$ to 4.3$)$ & 0.33 & 0.87 \\
\hline Diastolic & $82(11)$ & $79(9)$ & $-1.5(-4.2$ to 1.2$)$ & $-0.7\left(\begin{array}{ll}-3.3 & 1.9\end{array}\right)$ & 0.65 & 0.83 \\
\hline Mean arterial pressure & $103(11)$ & $100(10)$ & $-2.1(-4.8$ to 0.7$)$ & $-0.5(-3.2$ to 2.2$)$ & 0.42 & 0.74 \\
\hline \multicolumn{7}{|l|}{ Diabetes mellitus } \\
\hline HRQOL, 15D score & $0.856(0.108)$ & $0.868(0.096)$ & $0.002(-0.010$ to 0.013$)$ & $0.001(-0.010$ to 0.012$)$ & 0.91 & 0.84 \\
\hline Body mass index, kg/m2 & $31.0(5.5)$ & $31.6(6.2)$ & $-0.30(-0.54$ to -0.07$)$ & $0.03(-0.26$ to 0.32$)$ & 0.081 & 0.078 \\
\hline LDL-C, mmol/l & $2.49(0.94)$ & $2.38(0.83)$ & $0.03(-0.10$ to 0.15$)$ & 0.07 (-0.04 to 0.19$)$ & 0.61 & 0.74 \\
\hline $\mathrm{HbA} 1 \mathrm{C}, \mathrm{mmol} / \mathrm{mol}$ & $45.6(9.7)$ & $46.7(10.9)$ & $0.2(-0.8$ to 1.3$)$ & $-0.1(-1.4$ to 1.3$)$ & 0.75 & 0.91 \\
\hline \multicolumn{7}{|l|}{ Blood pressure $(\mathrm{mmHg})$} \\
\hline Systolic & $145(19)$ & $144(17)$ & $-2.4(-6.1$ to 1.3$)$ & $1.9(-5.4$ to 1.5$)$ & 0.86 & 0.54 \\
\hline Diastolic & $81(12)$ & $80(10)$ & $-0.1(-2.1$ to 1.9$)$ & $-0.1(-1.9$ to 1.6$)$ & 0.97 & 0.81 \\
\hline Mean arterial pressure & $102(12)$ & $101(10)$ & $-0.9(-3.2$ to 1.4$)$ & $-0.7(-2.9$ to 1.4$)$ & 0.94 & 0.89 \\
\hline
\end{tabular}

$S D$ standard deviation, $H R Q O L$ health-related quality of life, $L D L-C$ low-density lipoprotein cholesterol, HbA1C Haemoglobin A1C

** $P$-value for the differences in the changes between the intervention group and usual care group

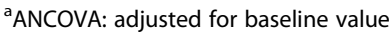

Our study did not find any significant changes of HRQOL. In the present study with 12 month follow-up, there may be several issues related to the small changes of HRQOL. Previously a Finnish population based study indicated that decrease of HRQOL is more significant in diabetes than in coronary heart disease or hypertension [20]. In cardiovascular diseases, older patients seem to experience less decrease in HRQOL compared with healthy ones [23]. It is plausible that in the present study, the patients with ischemic heart disease had quite stable treatment situation which is reflected by a low drop-out rate. In older diabetes patients, the higher HRQOL and better HbA1C balance have been associated [39]. In our study, diabetics had a good treatment balance on average. Hypertension, and especially the awareness of hypertension is known to slightly decrease the HRQOL $[40,41]$ although our study included only patients with known hypertension.

The earlier studies have shown a possible tendency to make care plans for patients with a worse therapeutic balance, which can affect the efficiency of the care plan $[11,15]$. In our study the patients were randomized and there was no selection according to therapeutic balance. Their therapeutic balance was good, particularly in diabetic patients' HbA1C, although BMI, LDL-C and blood pressure could be better in all the disease groups. However, the therapeutic balance was so good that improvement in any part of this kind of patient material would 


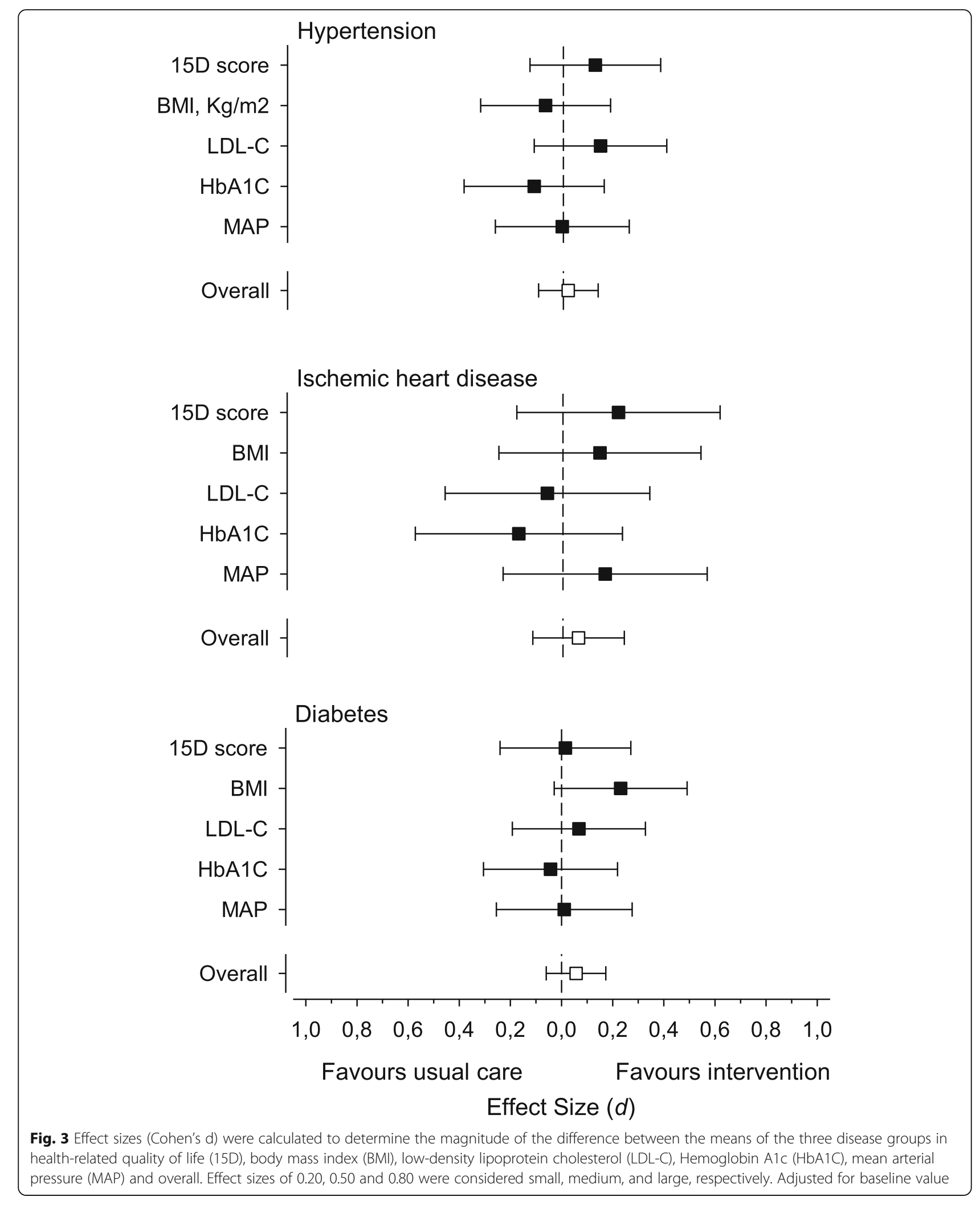


be quite challencing [42]. We can also consider these patients proactive because they were already registered and followed up in the health center and they were put in the automatic electronic health record calling system due to their chronic diseases. Thus, it is possible that part of the general goals of a care plan have already been achieved in the Finnish primary care, which can make it difficult to achieve significant further improvements with one intervention.

It seems that having a participatory care plan and being involved in the care plan process make patients more involved in their care and make their treatment more patient-centred $[3,11,13,14]$. This can lead to improved self-efficacy and better control of the clinical outcomes in the long run. However, given the relatively short follow-up in our study, the results may improve with more care plan rounds in the future. Twelve months is a comparatively short time for older patients to change their lifestyles and maintain new patterns of self-care. Many of them have suffered from their long-term diseases for a long time and have already adjusted their lifestyles to the disease. In this study, the intervention protocol and the UC were clearly different, but it is also possible that some physicians have made some changes in their practice and interaction with their patients in the UC group as well.

The strength of this study was that it was a randomized controlled study with a follow-up. The patients in our study were on average almost 70 years old with an average of more than two chronic diseases. Thus, they seem to represent the patients of Finnish primary care well. The number of patients was considerably high, and the dropout rate was low. The study was implemented in the everyday real-life work in the health center and consisted of the general patient groups treated in primary care. The study used real follow-up data, not only selfreports and also considered clinical outcomes. There are some limitations of this study that need to be acknowledged also. We did not know the duration of the diseases and if the patients who agreed to participate were more interested in taking care of themselves than patients that refused to participate. Although the patients seemed to be quite representative of primary care patients, the study was conducted in one health center, which may not warrant unconditional direct generalization of the results to other parts of Finland or internationally.

To better understand the impact of the participatory care planning, we need more knowledge of the changes in clinical measures with a longer follow-up among multimorbid patients. We also need to explore the ideas and attitudes that both the patients and health staff have on care plans and the whole care plan process.

We conclude that among the primary care patients with hypertension, ischemic heart disease or diabetes, treatment with a participating patient care plan was not significantly superior compared with usual care after a twelve-month follow-up. The follow-up period might have been short for this kind of intervention and setting, suggesting the need for a longer follow-up.

\section{Abbreviations \\ ANCOVA: Analysis of covariance; BMl: Body mass index; Cl: Confidence index; DBP: Diastolic blood pressure; HbA1C: Haemoglobin A1c; HRQOL: Health- related quality of life; LDL-C: Low-density lipoprotein cholesterol; MAP: Mean arterial pressure; n: Number; PPCP: Participatory patient care plan; SBP: Systolic blood pressure; SD: Standard deviation; \%: Percentage; UC: Usual care}

\section{Acknowledgements}

The authors wish to acknowledge the Siilinjärvi Health Center staff for collecting the data. Special acknowledgement goes to research nurses Nina Koskinen and Nina Serguskin for their work in organizing and collecting the data in the health center. We also wish to extend our gratitude to Pia Jauhiainen for data storage.

\section{Authors' contributions}

NT and PM contributed to the design of the study. NT, HK, PE, SS and PM contributed to the interpretation of the data. NT, HK and PM contributed to the data collection and data analysis. All authors critically revised the draft manuscript and approved the final content.

\section{Authors' information}

NT is a clinical lecturer in the University of Eastern Finland in general practice. HK is an expert in statistics. PE is a specialist in rheumatology. SS is a health psychologist and a university lecturer. PM is a professor in general practice.

\section{Funding}

Primary Health Care Unit of Northern Savo Hospital District and Siilinjärvi Health Center have participated in funding of the present study. NT has received grants from the Kuopio University Hospital Research Foundation, the Finnish Medical Foundation, the Finnish Foundation for General Practice and the General Practitioners in Finland. The funders did not take part in the study design, data collection and analysis or preparation and publishing of the manuscript.

\section{Availability of data and materials}

The data of the current study are not publicly available due to protection of individual privacy but are available from the corresponding author on reasonable request.

\section{Declarations}

Ethics approval and consent to participate

The study protocol was approved by the Research Ethics Committee of the Northern Savo Hospital District (410/2016). Written informed consent to participate was obtained from all participants.

Consent for publication

Not applicable.

\section{Competing interests}

The authors declare that they have no competing interests.

\section{Author details}

${ }^{1}$ Institute of Public Health and Clinical Nutrition, University of Eastern Finland, P.O. Box 1627, Fl-70211 Kuopio, Finland. ²Primary Health Care Unit, Kuopio University Hospital, Kuopio, Finland. ${ }^{3}$ Siilinjärvi Health Center, Siilinjärvi, Finland. ${ }^{4}$ Folkhälsan Research Center, Helsinki, Finland. ${ }^{5}$ Department of Medicine, Kuopio University Hospital, Kuopio, Finland. ${ }^{6}$ School of Educational Sciences and Psychology, University of Eastern Finland, Joensuu, Finland. 
Received: 10 January 2021 Accepted: 29 June 2021 Published online: 20 July 2021

\section{References}

1. Mittler JN, Martsolf GR, Telenko SJ, Scanlon DP. Making sense of "consumer engagement" initiatives to improve health and health care: a conceptual framework to guide policy and practice. Milbank Q. 2013;91(1):37-77. https://doi.org/10.1111/milq.12002.

2. Informed Medical Decisions Foundation. Available at: http://www.pcpci.org/ informed-medical-decisions-foundation. Accessed 11 Sept 2019.

3. Young CE, Boyle FM, Mutch AJ. Are care plans suitable for the management of multiple conditions? J Comorb. 2016;6(2):103-13. https://doi.org/10.152 56/joc.2016.6.79

4. Dineen-Griffin S, Garcia-Cardenas V, Williams K, Benrimoj SI. Helping patients help themselves: a systematic review of self-management support strategies in primary health care practice. PLoS One. 2019;14(8):e0220116. https://doi. org/10.1371/journal.pone.0220116.

5. WHO Ageing and Life Course. Available at: https://www.who.int/ageing/en/. Accessed 27 Aug 2019.

6. Statistics Finland. Tilastokeskus, väestöennuste. Available at: https://www.stat.fi/til/ vaenn/2019/vaenn_2019_2019-09-30_tie_001_fi.html. Accessed 27 Apr 2020.

7. European Commission Public Health. Available at: https://ec.europa.eu/hea Ith/. Accessed 112019

8. Komulainen J, Vuokko R, Mäkelä M. Structured health and care plan. Tampere: Terveyden- ja hyvnvoinnin laitos; 2011

9. Coulter A, Roberts S, Dixon A. Delivering better services for people with longterm conditions: building the house of care. London: King's Fund; 2013.

10. Morgan MA, Coates MJ, Dunbar JA. Using care plans to better manage multimorbidity. Australas Med J. 2015;8(6):208-15. https://doi.org/10.4066/A MJ.2015.2377.

11. Jansen DL, Heijmans M, Rijken M. Individual care plans for chronically ill patients within primary care in the Netherlands: dissemination and associations with patient characteristics and patient-perceived quality of care. Scand J Prim Health Care. 2015;33(2):100-6. https://doi.org/10.3109/02 813432.2015.1030167.

12. Mikkola I, Hagnas M, Hartsenko J, Kaila M, Winell K. A personalized care plan is positively associated with better clinical outcomes in the Care of Patients with Type 2 diabetes: a cross-sectional real-life study. Can J Diabetes. 2020; 44(2):133-8. https://doi.org/10.1016/j.jcjd.2019.05.003.

13. Burt J, Roland M, Paddison C, Reeves D, Campbell J, Abel G, et al. Prevalence and benefits of care plans and care planning for people with long-term conditions in England. J Health Serv Res Policy. 2012;17(1):64-71. https://doi.org/10.1258/jhsrp.2011.010172.

14. Reeves D, Hann M, Rick J, Rowe K, Small N, Burt J, et al. Care plans and care planning in the management of long-term conditions in the UK: a controlled prospective cohort study. Br J Gen Pract. 2014;64(626):568.

15. Patel MR, Valerio MA, Janevic MR, Gong ZM, Sanders $G$, Thomas $L$, et al Long-term effects of negotiated treatment plans on self-management behaviors and satisfaction with care among women with asthma. J Asthma. 2013:50(1):82-9. https://doi.org/10.3109/02770903.2012.743151.

16. Vuohijoki A, Mikkola I, Jokelainen J, Keinänen-Kiukaanniemi S, Winell K, Frittitta $L$, et al. Implementation of a personalized care plan for patients with type 2 diabetes is associated with improvements in clinical outcomes: an observational real-world study. J Prim Care Community Health. 2020;11: 2150132720921700.

17. Oksman E, Sisso M, Kuronen R. Väli-Suomen POTKU-hankkeen loppuraportti 2010-2012. 2013; Available at: https://docplayer.fi/23179300-Vali-suomenpotku-hankkeen-loppuraportti.html. Accessed 3 Jan 2020.

18. Morgan MA, Coates MJ, Dunbar JA, Reddy P, Schlicht K, Fuller J. The TrueBlue model of collaborative care using practice nurses as case managers for depression alongside diabetes or heart disease: a randomised trial. BMJ Open. 2013;3(1). https://doi.org/10.1136/bmjopen-002171.

19. Coulter A, Entwistle VA, Eccles A, Ryan S, Shepperd S, Perera R. Personalised care planning for adults with chronic or long-term health conditions. Cochrane Database Syst Rev. 2015;2015(3):CD010523. https://doi.org/10.1 002/14651858.CD010523.pub2.

20. Saarni SI, Härkänen T, Sintonen H, Suvisaari J, Koskinen S, Aromaa A, et al. The impact of 29 chronic conditions on health-related quality of life: a general population survey in Finland using 15D and EQ-5D. Qual Life Res. 2006;15(8):1403-14. https://doi.org/10.1007/s11136-006-0020-1.
21. Rothrock NE, Hays RD, Spritzer K, Yount SE, Riley W, Cella D. Relative to the general US population, chronic diseases are associated with poorer healthrelated quality of life as measured by the patient-reported outcomes measurement information system (PROMIS). J Clin Epidemiol. 2010;63(11): 1195-204. https://doi.org/10.1016/j.jclinepi.2010.04.012.

22. Samiei Siboni F, Alimoradi Z, Atashi V, Alipour M, Khatooni M. Quality of life in different chronic diseases and its related factors. Int J Prev Med. 2019;10:65.

23. Cepeda-Valery B, Cheong AP, Lee A, Yan BP. Measuring health related quality of life in coronary heart disease: the importance of feeling well. Int J Cardiol. 2011;149(1):4-9. https://doi.org/10.1016/j.jicard.2010.09.048.

24. Barker I, Steventon A, Deeny SR. Association between continuity of care in general practice and hospital admissions for ambulatory care sensitive conditions: cross sectional study of routinely collected, person level data. BMJ. 2017:356:j84.

25. Pereira Gray DJ, Sidaway-Lee K, White E, Thorne A, Evans PH. Continuity of care with doctors-a matter of life and death? A systematic review of continuity of care and mortality. BMJ Open. 2018;8(6):e021161. https://doi org/10.1136/bmjopen-2017-021161.

26. Baker R, Freeman GK, Haggerty JL, Bankart MJ, Nockels KH. Primary medical care continuity and patient mortality: a systematic review. Br J Gen Pract. 2020;70(698):e600-11. https://doi.org/10.3399/bjgp20X712289.

27. Gray DP, Sideway-Lee $K$, White E, Thorne A, Evans P. Improving continuity: THE clinica challenge. InnovAiT. 2016;9(10):635-45. https://doi.org/10.1177/1755738016654504.

28. Raivio R, Jääskeläinen J, Holmberg-Marttila D, Mattila KJ. Decreasing trends in patient satisfaction, accessibility and continuity of care in Finnish primary health care - a 14-year follow-up questionnaire study. BMC Fam Pract. 2014; 15(1):98. https://doi.org/10.1186/1471-2296-15-98.

29. Syrjä V, Parviainen L, Niemi A. Terveyskeskusten avosairaanhoidon järjestelyt 2019- Ulkoistukset, henkilöstö, työpanokset ja tehtäväsiirrot. Helsinki: Tutkimuksesta tiiviisti; 2019. p. 51.

30. Sillinjärvi municipality. Population: Siilinjärvi; 2017. Available at: https://www.siilinja rvi.fi/minun-siilinjarvi/tietoa-silinjarvesta/tilastot/vaesto/. Accessed 28 Oct 2018

31. Tusa N, Kautiainen $H$, Elfving P, Sinikallio S, Mäntyselkä P. Relationship between patient activation measurement and self-rated health in patients with chronic diseases. BMC Fam Pract. 2020;21(1):225-y.

32. Sintonen $\mathrm{H}$. The $15 \mathrm{D}$ instrument of health-related quality of life: properties and applications. Ann Med. 2001;33(5):328-36. https://doi.org/10.3109/07853 890109002086.

33. Alanne S, Roine RP, Räsänen P, Vainiola T, Sintonen H. Estimating the minimum important change in the 15D scores. Qual Life Res. 2015;24(3): 599-606. https://doi.org/10.1007/s11136-014-0787-4

34. Beck AT, Ward CH, Mendelson M, Mock J, Erbaugh J. An inventory for measuring depression. Arch Gen Psychiatry. 1961;4(6):561-71. https://doi. org/10.1001/archpsyc.1961.01710120031004.

35. Kasari D. Effect of exercise and fitness on serum lipids in college women University of Montana; 1976.

36. Hicks VL, Stolarczyk LM, Heyward VH, Baumgartner RN. Validation of nearinfrared interactance and skinfold methods for estimating body composition of American Indian women. Med Sci Sports Exerc. 2000;32(2): 531-9. https://doi.org/10.1097/00005768-200002000-00041.

37. Jacob C. Statistical power analysis for the behavioral sciences. 2nd ed. Hillsdale: Lawrence Erlbaum Associates; 1988.

38. Hedges L, Ingram O. Statistical methods for meta-analysis. 1st ed. London: Academic Press; 1985

39. Aro AK, Karjalainen M, Tiihonen M, Kautiainen H, Saltevo J, Haanpää M, et al. Glycemic control and health-related quality of life among older homedwelling primary care patients with diabetes. Prim Care Diabetes. 2017; 11(6):577-82. https://doi.org/10.1016/j.pcd.2017.07.001.

40. Trevisol DJ, Moreira LB, Kerkhoff A, Fuchs SC, Fuchs FD. Health-related quality of life and hypertension: a systematic review and meta-analysis of observational studies. J Hypertens. 2011;29(2):179-88. https://doi.org/10.1 097/HJH.0b013e328340d76f.

41. Korhonen PE, Kivelä SL, Kautiainen H, Järvenpää S, Kantola I. Health-related quality of life and awareness of hypertension. J Hypertens. 2011;29(11): 2070-4. https://doi.org/10.1097/HJH.0b013e32834bbca7.

42. Smith SM, Wallace E, O'Dowd T, Fortin M. Interventions for improving outcomes in patients with multimorbidity in primary care and community settings. Cochrane Database Syst Rev. 2016:3:CD006560. 


\section{Publisher's Note}

Springer Nature remains neutral with regard to jurisdictional claims in published maps and institutional affiliations.

- fast, convenient online submission

- thorough peer review by experienced researchers in your field

- rapid publication on acceptance

- support for research data, including large and complex data types

- gold Open Access which fosters wider collaboration and increased citations

- maximum visibility for your research: over $100 \mathrm{M}$ website views per year

At $\mathrm{BMC}$, research is always in progress. 